\title{
Homossexualidades: Espaço em uma Revista Especializada?
}

\author{
Maria de Fátima Evangelista Mendonça Lima ${ }^{1}$ \\ Departamento de Ciências Humanas da Universidade Federal de Mato Grosso do Sul, \\ Campo Grande, MS, Brasil \\ Eder Ahmad Charaf Eddine \\ Fundação Universidade Federal do Tocantins, Palmas, TO, Brasil \\ Programa de Pós-Graduação em Educação da Universidade de São Paulo, \\ São Paulo, SP, Brasil
}

\begin{abstract}
Resumo
A partir da década de 1990, no Brasil, assiste-se a um movimento de combate a discriminações e estigmatizações contra práticas homossexuais. Este estudo procura investigar o discurso psicológico especializado sobre as homossexualidades veiculado pela revista Viver Psicologia, um periódico que abrange não só o profissional de psicologia, mas, também, acadêmicos de diversas áreas do conhecimento e a população em geral. A intenção aqui não é a de avaliar a estrutura teórica desses discursos, validade ou paradigmas de apoio, mas trazer à tona orientações dos profissionais psi acerca das homossexualidades, oferecidas por meio de um veículo de publicação de fácil acesso ao leitor. Para tanto, foi realizada uma leitura interpretativa dos textos de vinte e cinco exemplares da revista, produzidos por profissionais através da técnica de análise de conteúdo - perfazendo um período de dois anos (junho de 2002 a junho de 2004). Os resultados mostram que nos raros momentos em que o tema homossexualidade é alvo de publicação, na revista, o que denota uma forma de preconceito, encontra-se respaldado pela teoria psicanalítica, a qual considerou, por muito tempo, homossexualidade como doença.
\end{abstract}

Palavras-chave: Homossexualidade, preconceito, estigmatização, mídia, psicologia.

\section{Homosexualities: Space in a Specialized Journal?}

\begin{abstract}
From the 1990s, we are witnessing a movement to combat discrimination and stigmatization against homosexual practices in Brazil. This study aims to investigate the psychological discourse specialized on homosexuality published by the magazine 'Viver Psicologia', a journal that covers not only psychology professionals, but also academics from various fields of knowledge and the general population. The aim of this research is not to evaluate the theoretical structure of these discourses, validity or support paradigms, but assessing psychology professionals' guidance about homosexuality, offered through a publishing vehicle easily accessible to the readers. To this end, through the technique of content analysis, we performed an interpretative reading of texts from twenty-five issues of the magazine produced by professionals for a period of two years (June 2002 to June 2004). The results show that in the rare cases in which the theme homosexuality is published in the magazine - which denotes a form of prejudice - it is backed by the psychoanalytic theory, which had dealt with homosexuality as a disease for a long time.
\end{abstract}

Keywords: Homosexuality, prejudice, stigmatization, media, psychology.

Endereço para correspondência: Rua Domingos Marques, 903, Jd. Bela Vista, Campo Grande, MS, Brasil 79003-190. E-mail: fatimamlima10@gmail.com e ederahmad@mail.uft.edu.br 


\section{Homosexualidades: ¿Espacio en una Revista Especializada?}

\section{Resumen}

Desde la década de 1990 observamos un movimiento para combatir la discriminación y estigmatizaciones contra las prácticas homosexuales en Brasil. Este estudio pretende investigar el discurso de la psicología especializado en la homosexualidad, publicado por la revista Viver Psicologia, un periódico que abarca no solamente al profesional de psicología, sino también a académicos de diversos campos del conocimiento y a la población en general. La intención aquí no es la de evaluar la estructura teórica de esos discursos, la validez o los paradigmas de apoyo, mas traer a colación la orientación de los profesionales de la psicología sobre la homosexualidad, ofrecida a través de un medio editorial fácilmente accesible al lector. Para ello, a través de la técnica de análisis de contenido realizamos una lectura interpretativa de textos de veinticinco ejemplares de la revista producidos por profesionales, por un período de dos años (junio de 2002 a junio de 2004). Los resultados muestran que en las raras ocasiones en que el tema homosexualidad es objeto de publicación en la revista - lo que denota una forma de prejuicio este está respaldado por la teoría psicoanalítica, que durante mucho tiempo trato a la homosexualidad como una enfermedad.

Palabras clave: Homosexualidad, prejuicio, estigmatización, medios de comunicación, psicología

A discriminação por orientação sexual vem sofrendo inúmeras transformações nos últimos anos, tanto nos países desenvolvidos quanto nos em desenvolvimento, transformações que são referidas na ciência, literatura, cinema e nos veículos de comunicação em geral.

Pode-se verificar na Medicina e na Psicologia, por exemplo, que a homossexualidade foi tratada como patologia, até muito recentemente.

Somente em 1973, a American Psychiatric Association (APA), e em 1992, a Organização Mundial da Saúde (OMS), removerem a homossexualidade da lista oficial dos desvios mentais (Herek, 2000). Efetivamente, em 1985, o Conselho Federal de Medicina retira a homossexualidade da condição psiquiátrica (Scardua \& Souza, 2006).

No campo da Psicologia, o Conselho Federal de Psicologia (CFP), apenas em 1999, se manifesta oficialmente a respeito da homossexualidade. A Resolução n. 001/1999 é um marco na defesa dos direitos humanos, estabelecendo normas de atuação para os psicólogos em relação à orientação sexual, vedando aos mesmos atuarem em propostas de tratamento e de cura da homossexualidade. Através da referida Resolução, o CPF marca a posição da Psicologia, afinada à APA e à OMS, de não reconhecer a homossexualidade como doença, distúrbio ou perversão e sim como uma das possibilidades de expressão da sexualidade, como qualquer outra. Em seu Art. $2^{\circ}$ estabelece, ainda, que "os psicólogos devem contribuir, com seu conhecimento, para uma reflexão sobre o preconceito e o desaparecimento de discriminações e estigmatizações contra aqueles que apresentam comportamentos ou práticas homoeróticas" (CFP, 1999).

As políticas públicas para homossexuais vêm ganhando espaço, gradativamente, no Brasil. No período de 2001 a 2010, no Brasil, foram produzidos documentos promovidos pelo Poder Executivo, tais como: o "Programa Brasil Sem Homofobia" (Ministério da Saúde, 2004), o "Plano Nacional de Promoção da Cidadania e Direitos Humanos LGBT Lésbicas, Gays, Bissexuais, Travestis e Transexuais", o "Programa Nacional de Direitos Humanos I", o "Programa Nacional de Direitos Humanos II" e o "Programa Nacional de Direitos Humanos 3". São manifestações do compromisso do Governo Federal com demandas históricas do movimento LGBT, em que pese ser estreita a possibilidade de assegurar direitos para essa população tão somente por meio dessas iniciativas (Mello, Avelar, \& Maroja, 2012):

Afinal, políticas públicas objetivam definir ações e programas capazes de gerar maior efetividade para direitos previstos em nor- 
mas legais, o que ainda não acontece no caso da maior parte dos direitos sexuais no Brasil, especialmente no tocante à igualdade na esfera pública entre todas as pessoas independentemente de orientação sexual e identidade de gênero. (p. 307)

Além disso, em maio de 2011, o Supremo Tribunal Federal (STF) reconhece a união homoafetiva e, em maio de 2013, o Conselho Nacional de Justiça (CNJ) aprova e obriga os cartórios de todo o País a realizar o casamento homossexual.

Em suma, em termos de legislação, a questão da homossexualidade teve avanço no Brasil. Mas, apesar das transformações, como já foi dito, a rede de significados que estabelece a assimetria de direitos ainda está desarticulada. A partir do transtorno da ordem produzida por uma relação homossexual, os homossexuais são invisibilizados e estigmatizados socialmente.

Desde a década de 1980, a homossexualidade vem sendo alvo dos veículos de comunicação, com a descoberta da AIDS. Esta, inicialmente estigmatizada como Câncer Gay, em virtude de os homossexuais - principalmente o masculino - terem sido considerados culpados pelo surgimento e disseminação da epidemia; atualmente, mesmo que a AIDS atinja todas as camadas sociais e de gênero, ainda há uma forte relação entre AIDS e homossexualidade (Nunan, 2003). Com essa visibilidade, mesmo preconceituosa, os homossexuais ganham espaço, sendo observados, também, como consumidores, papel este importante na nossa sociedade capitalista.

Os discursos cientificos e as práticas sobre a sexualidade, com suas verdades e seus valores morais, estabelecem o que deve ser praticado, influindo nas subjetividades e nas configurações individuais concernentes aos prazeres e ao corpo (Madlener \& Dinis, 2007).

De acordo com Novelino (1989), o discurso psi, especializado, insere-se ao patrimônio cultural da sociedade, estabelecendo-se como versão verdadeira do universo e das relações sociais. Produz uma base interpretativa para a compreensão da vida e a estruturação da experiência humana, seguindo o cotidiano de atividades das pessoas, notadamente nas áreas da sexualidade, casamento e criação dos filhos/as. Uma das vias de difusão desse discurso é a mídia, que propaga as afirmações das ciências psicológicas para as diversas parcelas da sociedade. Dada a condição privilegiada dos profissionais psi na confecção de modelos, e da mídia como um dos principais canais de difusão do discurso especializado, parece adequado investigar a composição desses modelos presentes na mídia especializada de cunho extra-acadêmico. Nesse sentido, o objetivo desse trabalho é analisar o discurso engendrado pelos especialistas psi em relação à homossexualidade, através da revista Viver Psicologia.

\section{Conceituando Homossexualidades}

O conceito de homossexualidade é recente na história da humanidade (Mott, 2003). Entende-se a homossexualidade como uma construção social, baseada nas relações sociais de poder que configuram a estrutura do preconceito em determinada sociedade. Essa construção social é resultado de processos sócio-históricos associados à relação dialética estabelecida entre indivíduo e sociedade. Neste artigo, utiliza-se o plural homossexualidades, abrangendo tanto o homossexual masculino quanto o feminino, como contraposição ao essencialismo psicológico discutido neste texto.

Pode-se dizer, então, que nenhum dos termos utilizados para designar uma pessoa ou a sexualidade correspondem a realidades permanentes e descontextualizas da história em que são definidos, ou seja, a noção de homossexualidades é historicamente datada, pois depende da noção de sexualidade, que é, por sua vez, igualmente histórica (Foucault, 1996).

A diferenciação sexual é recente na nossa história - data do início do Século XIX - e trouxe à tona a discussão da diferença de gênero, surgindo, também, a diferenciação sexual do psiquismo (Nunan, 2003).

Nunan (2003), retomando o modelo expresso por Thomas Laqueur, sobre a concepção científica de sexualidade existente nos Séculos XVII e XVIII, comenta que no one-sex-model, a mulher era um homem invertido e inferior, contudo, fundamental para a reprodução da espécie humana. Ao passar para um modelo two-sex-model, a 
mulher não é mais o inverso do homem, invertido, agora, é o homossexual.

A partir de então, os homossexuais, juntamente com outros perversos e as mulheres histéricas, passaram a ser estudados pela Psiquiatria, sendo vistos como uma grave ameaça à família, à raça e à sociedade e, portanto, objeto de intervenções e de controles (Nunan, 2003).

Nesse sentido, surgem as tentativas de cura da homossexualidade (Nunan, 2003). Propõe-se, inicialmente, a abstinência, forçada, baseada na hipótese de que o homossexual busca somente o prazer sexual; posteriormente, foi utilizada a hipnose como possibilidade de fazer os homens homossexuais desejarem as mulheres. No século $\mathrm{XX}$, o discurso médico-científico toma a hipótese de que a homossexualidade é determinada biologicamente, o que ocasionou uma série de tentativas hormonais e cirúrgicas, visando transformar homossexuais em heterossexuais. Paralelamente a essas tentativas de cura, a noção de homossexualidade, integrada à Psicologia e à Psiquiatria, passou a ser explicada como produto das histórias individuais.

\section{A Psicologia e os Estudos sobre a Homossexualidade}

Quando a Psicologia é visitada, a respeito das homossexualidades, se encontra de entrada, os estudos de Sigmund Freud que, considerado o criador da Psicanálise, foi o teórico que mais teve influência nos estudos sobre a homossexualidade. Freud (1996b/1910a) em seu livro As Aberrações Sexuais, chama o homossexual de invertido, elencando os diversos tipos de comportamentos dos invertidos:

As pessoas em questão comportam-se de maneira muito diversificada em vários aspectos: (a) podem ser invertidos absolutos, ou seja, seu objeto sexual só pode ser do mesmo sexo, enquanto o sexo oposto nunca é para eles objeto de anseio sexual, mas antes os deixa frios ou até lhes desperta aversão sexual; (b) podem ser invertidos anfígenos (hermafroditas sexuais), ou seja, seu objeto sexual tanto pode pertencer ao mesmo sexo quanto ao outro; falta à inversão, portanto, $\mathrm{o}$ caráter de exclusividade; e (c) podem ser invertidos ocasionais, ou seja, em certas condições externas, dentre as quais destacam-se a inacessibilidade do objeto sexual normal e a imitação, podem tomar como objeto sexual uma pessoa do mesmo sexo e encontrar satisfação no ato sexual com elas. (Freud, 1996b/1910a)

Para Freud (1996a/1908), os homossexuais ou os invertidos, ao sublimarem, isto é, ao colocarem sua energia psíquica à disposição da arte e da intelectualidade aplicam "seu instinto sexual para a sublimação cultural". Em seu livro Leonardo da Vinci e uma Lembrança de sua Infância (1996c/1910b), Freud argumenta que a sublimação da libido faz com que o indivíduo não se preocupe com temas sexuais, afirmando que o artista sublimará sua sexualidade: "se refletirmos acerca da ocorrência em Leonardo do poderoso instinto de pesquisa, a atrofia de sua vida sexual fica restrita ao que poderíamos chamar de homossexualidade ideal [sublimada]".

Ao estudar um caso de homossexualidade numa mulher, Freud (1996d/1920) relata que: "Não compete à psicanálise solucionar o problema do homossexualismo ... Uma mulher que já se sentiu ser um homem e amou a maneira masculina, dificilmente permitirá que a forcem a desempenhar o papel de mulher".

Segundo Freud (1996b/1910a), os homossexuais possuem um "comportamento variado no juízo que fazem da peculiaridade de sua pulsão sexual". Alguns aceitam a inversão como algo natural, tal como os normais aceitam a orientação de sua libido, e defendem energicamente sua igualdade de direitos com os normais. Nesta citação, percebe-se que há homossexuais que não se consideram doentes e lutam por igualdade de direitos, e que Freud não os condena por isso.

É importante ressaltar que, em relação à época - a homossexualidade era considerada doença, destacando a existência do que Freud chamou de invertidos - a visão de homossexualidade de Freud pode ser vista como progressista e mais compreensiva que a de vários de seus seguidores, pois compreendia os seres humanos como psiquicamente homossexuais (Costa, 1992). Esta visão mais compreensiva e humana 
de Freud é vista em uma famosa carta que escreve para a mãe de um homossexual, em 9 de abril de 1935, onde o autor relata que vários indivíduos altamente respeitáveis são homossexuais e que é uma grande injustiça perseguir a homossexualidade como crime.

Deduzo de sua carta que seu filho é homossexual. . . . Ao solicitar a minha ajuda, a senhora revela a intenção, suponho eu, de obter que eu abula a homossexualidade e faça com que a heterossexualidade assuma o seu lugar. A resposta é que, de maneira geral, não temos possibilidade de consegui-lo. (Freud, 1935, citado por Jones, 1979, pp. 738-739)

Contudo, nem todos os seguidores de Freud comungavam com essa visão, conforme aponta Ceccarelli (2008, p. 77):

A posição freudiana em relação à questão [da homossexualidade] não obteve consenso entre os analistas, chegando mesmo a provocar polêmica entre a Sociedade Psicanalítica de Viena e a de Berlim. Esta, dirigida por Abraham, considerava que os homossexuais eram incapazes de exercer a profissão de analista, pois a análise não os "curariam" da "inversão" que sofrem.

Segundo o autor, após realizar uma revisão dos textos de Freud sobre a homossexualidade, embora haja algumas ambiguidades nos escritos freudianos, a homossexualidade é vista como "uma posição libidinal, uma orientação sexual, tão legítima quanto a heterossexualidade" (Ceccarelli, 2008, p. 74).

Para ilustrar sobre como algumas posições de psicanalistas contemporâneos são divergentes da do criador da psicanálise, destaca-se um importante teórico brasileiro e sua fala sobre a homossexualidade. Zimerman (2004), em seu livro Manual de Técnica Psicanalítica: Uma Re-Visão, escrevendo sobre a homossexualidade, diz que:

. . e é necessário deixar claro que, antes de ser enquadrada em uma única categoria nosológica - como perversão, por exemplo - a homossexualidade deve ser compreendida como uma síndrome, ou seja, diversas causas etiológicas podem manifestar-se por meio de uma mesma manifestação sistemática aparente. Cabe uma analogia com o surgimento de uma "febre", a qual, por si só, de forma nenhuma pode ser considerada como um quadro clínico específico, mas, sim, como uma síndrome febril que tanto pode ser devida a um resfriado banal, como pode traduzir uma pneumonia ou qualquer outro processo infeccioso, indo até a possibilidade extrema de um processo cancerígeno ou de uma gravíssima septicemia. (Zimerman, 2004, p. 275)

Observa-se que a publicação do referido livro é feita quando a homossexualidade já não é mais considerada doença, salientando que nem mesmo Freud fez uma analogia tão estigmatizante sobre o assunto. Neste sentido, Portinari (1989) destaca o quanto "Freud se mostrou lúcido e cauteloso no que diz respeito ao tema da homossexualidade feminina, bem mais do que vários dos seus seguidores" (p. 85).

Costa (1992) afirma que os sujeitos auto-declarados homossexuais, carregam um fardo moral e psíquico extremamente difícil e, que, "uma vez etiquetados assim, são constantemente identificados por suas preferências sexuais, as quais, por seu turno, são moralmente desaprovadas, seja pelo ridículo, seja pela classificação, no rol das patologias médico-psiquiátricas ou mesmo psicanalíticas" (p. 31).

Por outro lado, o referido autor, ao relatar sobre a análise, no sentido psicanalítico, e sobre casos de sujeitos queixando-se de homossexualismo, medo de homossexualismo ou suspeita de homossexualismo diz que:

A noção de homossexualidade como perversão parece-me indefensável pelo simples fato de não dispormos ainda, em psicanálise, de uma teoria sobre o fenômeno perverso que seja ao mesmo tempo coerente nos próprios termos, e razoavelmente aplicável aos casos diagnosticados como casos de homossexualismo. (Costa, 1992, p. 85)

Assim sendo, para Costa (1992), "a "estrutura homossexual' não se funda em nenhuma hipótese psicanalítica consistente" (p. 86). As citações acima, baseadas na teoria psicanalítica, parecem estigmatizar o sujeito homosse- 
xual, pois autores declarados psicanalistas, ora afirmam a homossexualidade como perversão (Zimerman, 2004), ora querem trabalhá-la como meramente atração erótica (Costa, 1992).

A Psicologia Comportamental, por sua vez, por meio de suas técnicas, tratou de casos de homossexualidade. D. M. S. Campos (1983) ao descrever o Princípio da Prática Negativa, relata que:

Este princípio resultou da sistematização do princípio da saciação, em que se fazendo ocorrer um comportamento, muitas vezes, em sucessão, o mesmo tende a não mais ocorrer. Dunlap desenvolveu seu método baseado neste princípio, conseguindo êxito no tratamento e eliminação de vários distúrbios, entre os quais gagueira, hábito de chupar o dedo e até mesmo homossexualidade.

(D. M. S. Campos, 1983, p. 28)

Não se pretende aqui explicar os conceitos de Modificação de Comportamento, mas apenas referir-se sobre a ação da Psicologia ao tentar curar a homossexualidade. Essas teorias sustentaram a homossexualidade como distúrbio, sem questionar se esta seria uma doença ou mais uma forma de viver a sexualidade.

Como lembram Lacerda, Pereira e Camino (2002, p. 167), boa parte dos psicólogos brasileiros, sem expressar um preconceito explícito contra homossexuais, "trata a homossexualidade como um distúrbio que deve ser assumido ou se possível superado".

\section{O Poder das Indústrias da Mídia}

A mídia ou indústria cultural, resultado de um processo histórico que acompanhou o surgimento das sociedades modernas, atua na produção e difusão de bens simbólicos em prol de sua mercantilização, tendo, assim, um impacto fundamental na maneira como as pessoas agem e interagem umas com as outras (Thompson, 1995).

Estudos (Adorno \& Horkheimer, 1985; Le Bon, 1911/2001; Novelino, 1989; Thompson, 1995, por exemplo) mostram a influência exercida pelos meios de comunicação na constituição do psiquismo do individuo. Em Les Opinious et le Croyances - As Opiniões e as Crenças - Le Bon (1911/2001) mostra a força que os veículos de comunicação têm na propagação de ideias, crenças e valores, tendo tido, inclusive, o poder de arruinar civilizações.

Segundo Adorno e Horkheimer (1985), o domínio da indústria cultural, na sociedade capitalista, impossibilita que sejam formados indivíduos capazes de refletir e agir de forma consciente, tornando-se, os mesmos, automatizados, sensíveis à adesão dos ideários por ela propalados, a qual se estrutura por meio de um sistema integrado, de forma que cada instância é lógica em si mesma e todas as são na sua totalidade.

Para Novelino (1989), a mídia realiza função importante na disseminação e produção de modelos e quadros de valores, dirigindo as ações cotidianas, moldando a realidade psicológica e produzindo a subjetividade.

Desta forma, pode-se dizer que os veículos de comunicação social, ao lado de outras instâncias sociais, desempenham um papel de mediação ideológica nas sociedades modernas, na qual, ao mesmo tempo em que participam do processo de constituição dos sujeitos, retratam um contexto cultural e social construído e transformado por estes sujeitos. O que significa dizer que esse não é um processo no qual os sujeitos participam como meros receptores. Ao invés disso, estão implicados participando ativamente, ou seja, os significados veiculados pela mídia são apropriados pelos sujeitos e transformados em mediações na constituição destes.

\section{Metodologia}

Este estudo engloba a análise de 25 exemplares da revista Viver Psicologia, no período que vai de junho de 2002 a junho de 2004. Trata-se de uma amostra por conveniência, considerando que foram utilizados os exemplares que um dos autores tinha em seu poder.

Nas revistas analisadas, a busca pelo termo homossexualidade se deu pela ampliação da expressão através das palavras: homossexual, homossexualidade, homossexualismo, homoerotismo e homoafetividade, não importando o tí- 
tulo, o assunto e a seção em que estas aparecem. Para a análise, foram utilizados apenas artigos, ensaios e matérias assinadas, por expressarem a opinião de alguém, seja da revista ou de quem assina.

A intenção aqui não é a de avaliar a estrutura teórica dos textos, validade ou paradigmas de apoio, mas trazer à tona orientações dos profissionais psi acerca da homossexualidade, oferecidas por meio de um veículo de publicação de fácil acesso ao leitor.

A análise dos textos foi feita com o auxílio da proposta de Bardin (1979), que define análise de conteúdo como:

Um conjunto de técnicas de análise das comunicações visando obter, por procedimentos sistemáticos e objetivos de descrição do conteúdo das mensagens, indicadores (quantitativos ou não) que permitam a inferência de conhecimentos relativos às condições de produção/recepção (variáveis inferidas) destas mensagens. (p. 42)

A análise de conteúdo objetiva levantar dados da mensagem buscando encontrar significados no discurso, aparentes e implícitos; para tanto, realiza cortes e elenca categorias. Para Rosenbaum (1998):

A característica de subjetividade é inegável neste sistema de análise, pois os cortes efetuados, a eleição de categorias, assim como a inferência de significados que são efetivados pelo(a) pesquisador(a), seguem suas determinações e seus constructos teóricos. A objetividade a que a análise se propõe é relativa à etapa de coleta dos dados veiculados na mensagem (ou texto), em estudo, que juntamente com sua caracterização, devem ser feitas de forma clara, seguindo regras pré-estabelecidas, buscando-se obter resultados fidedignos à utilização do instrumento, não se perdendo na subjetividade do pesquisador neste processo. (pp. 63-64)

Como salienta Novelino (1989), "uma das características da técnica de análise de conteúdo é a simultaneidade no processo de investigação, da coleta de dados e a análise dos mesmos" (p. 56). Isso significa dizer que os dados são analisados simultaneamente à coleta, o que requer a atenção permanente do investigador para evitar de afastar-se do eixo proposto e da base teórica que fundamenta o caminho explorado.

O trabalho de análise foi realizado em 3 etapas:

1. A primeira etapa foi destinada a uma leitura global do todo de cada revista; é o que Bardin (1979) denomina de "leitura "flutuante". Esta leitura inicial objetivou um contato inicial com o material a ser analisado, buscando perceber quais aspectos chamam atenção e geram questões a serem detalhadas em outra etapa. Uma grade de análise construída em torno do objetivo do trabalho serviu de guia auxiliar para realçar os aspectos relevantes ao tema;

2. Na segunda etapa, iniciou-se a análise inferencial propriamente dita, que constou de uma releitura detalhada dos textos e subsequentes recortes dos mesmos em trechos significativos (unidades de análise) - parágrafos, sentenças, etc. - para a temática abordada. O sentido desses pedaços, retirados para análise, localiza-se em sua relação com o texto mais amplo (unidade de contexto) no qual se insere, integrado aos objetivos propostos;

3. Finalmente, a construção das categorias que foram estruturadas, de maneira artesanal, com os elementos dados explicitamente pelos conteúdos analisados, pelas significações incrustadas que impregnam esses conteúdos e pela perspectiva temática assumida ao longo da interpretação.

Configura-se como unidade de análise, o tema. O córpus da pesquisa compõe-se do conjunto dos textos das revistas, que tratam direta ou indiretamente sobre a homossexualidade.

Dessa maneira foi-se esboçando, pouco a pouco, o ideário de sexualidade - ligado aos papéis estereotipados de homem e de mulher e praticamente ausente a discussão sobre o tema da homossexualidade - desenhado pela máquina conceitual psi. Associada a este termo- homossexualidade - foi se desenhando a imagem da perversão, do desvio do comportamento e das práticas sexuais normais ou assim consideradas. 


\section{Resultados e Discussão}

Trata-se da análise de revista - cuja circulação foi paralisada em 2004 - de grande aceitação entre os estudantes e os profissionais de psicologia, na época, o que pode ser percebido ao serem lidas as cartas e os e-mails enviados à editora e publicados na seção cartas. O público leigo também envia cartas e e-mails para a seção cartas e seção divã, esta última, rigorosamente respondida por psicólogo.

A publicação é composta basicamente pelas seguintes partes: Matéria de Capa, Seções, Artigos, Reportagens, Colunas e Carta ao Leitor.

A Matéria de Capa é a porção marketing da revista, a qual norteia todas as outras partes da publicação. A parte Seções é composta basicamente pela seguinte divisão: Divã, Cartas, In-sights, Livros, Internet e Agenda. A seção Divã é sempre assinada por um(a) psicólogo(a) que responde cartas de leitores. A seção Cartas representa o espaço onde as pessoas enviam sugestões, reclamações, elogios e solicitações. A seção In-sights, assinada, também, por psicólogo(a), divulga pesquisas e estudos, fatos e novidades.

Já a seção Internet, divulga páginas da internet referentes à matéria de capa, enquanto a seção agenda é destinada a mostrar os eventos da revista. Finalmente, a seção Entrevista, organizada pela editoração, relacionada ou não com a matéria de capa, destina-se a entrevistar profissionais de diversas áreas do saber.

O exemplar n. 115, cuja capa intitulada " 40 Anos de Psicologia no Brasil", traz comentário sobre a homossexualidade. $\mathrm{O}$ autor destaca:

Quando um pai é eliminado, por gestão materna, deixa espaço para a perversão ou a psicose. Isso acontece porque é ele quem coloca limites na ditadura materna e o ser humano só se estrutura em triângulo, ou seja, precisa-se de pelo menos três ângulos: pai, mãe e filho. Se o pai está ausente, só restam mãe e filho, e a única figura geométrica que se pode fazer com dois pontos é uma linha. Esta linha de montagem, viúva, rompe a linhagem, já que seu efeito mais notável é a homossexualidade e a psicose.
Sem pai não há filhos, por mais que as mães reclamem. (Goldin, 2002, p. 38)

Neste trecho, percebe-se o quanto preconceituosa é a afirmação do autor, comparando a prática sexual e afetiva do homossexual à perversão. Este conceito, que tem como arcabouço teórico a psicanálise, estigmatiza a homossexualidade. O autor diz ainda que, se o filho (sem pai) não se tornar homossexual, será psicótico, visão heterossexista e machista da educação dos filhos e da estrutura familiar, estrutura esta já criticada por diversos autores.

No exemplar n. 120, o assunto aparece na seção "Divã". A pergunta da leitora é a seguinte:

Conheço um rapaz que na adolescência teve um relacionamento com um homem casado e com filhos, em troca de dinheiro. Ele diz que fez isso só por dinheiro e que sempre se sentiu heterossexual, mas atualmente se sente muito culpado por ter se prestado a um papel tão sujo. É possível que esse jovem, hoje (depois de seis anos), possa manifestar traços homossexuais? Isso é comum?

A resposta é a seguinte:

É importante salientar que a procura por uma identidade, em especial a sexual, ocorre durante a adolescência. Nesse sentido, ter fantasias ou experiências homossexuais é comum nessa fase de intensa curiosidade sobre sentimentos e preferência sexual. Isso, porém, não determina a homossexualidade na vida adulta. Em regra, os adolescentes vivem os seus impulsos sexuais de forma bastante tumultuada. Se, além disso, o sexo é vivido sob ameaças ou com outras finalidades, a pessoa o assimila como algo sujo, passível de reprovação. Nesse caso, a conotação negativa dessa experiência costuma marcar profundamente, perseguindo-o como um "fantasma" do passado que não a deixa em paz. No entanto, o fato de alguém ter vivido uma experiência homossexual no passado não determinará necessariamente a sua orientação sexual. $\mathrm{O}$ que as pessoas aprendem com as experiências passadas é que elas não precisam repetir no presente o que não gostaram. E quando esse aprendizado se mostra difícil no momento atual, a 
ajuda profissional é o caminho mais indicado. (Reis, 2003, p. 4)

Pode-se notar, no trecho acima, que o tema homossexualidade não surge de forma clara, mas de forma camuflada. Além disso, a fala da autora é ameaçadora para o adolescente, principalmente para aquele que já sabe sua orientação homossexual, pois este poderá pensar que está fazendo algo "sujo, passível de reprovação".

Como argumenta Berger (1980), o discurso psi, especializado, fornece uma base interpretativa para a apreensão da vida e a organização da experiência humana, notadamente no âmbito da sexualidade, casamento e educação. Segundo Guattari e Rolnik (1986): "pensam por nós, organizam por nós a produção e a vida social" (p. 41), sendo a mídia um dos canais de difusão desse discurso (Buitone, 1981).

Para Novelino (1989), a presença dos especialistas psi na constituição de modelos de sexualidade e, consequentemente, enquanto autoridade capaz de regular essa experiência, é recente. Sua ascendência ao posto de tutor da dinâmica familiar é proporcional à gradativa infantilização dos indivíduos, função vital da economia subjetiva capitalista.

No exemplar 121, texto intitulado "Questão de Gênero", discute o falecimento do antigo macho e o nascimento do novo homem. Para o autor, essa transformação se deu à custa de muita dor. Afinal, "a crise da masculinidade está no centro da maior parte dos conflitos e da violência da vida moderna" (Zominari, 2003, p. 34). Segundo o referido autor:

São características que, historicamente cultuadas, acabaram por compor o herói, arquétipo óbvio da masculinidade a dominar a caça e guerra, uma forte influência para todos os homens até hoje. Por tudo isso, tal masculinidade precisará sempre ser checada e provada, pois, afinal de contas, além da proteção à vida, a reprodução sexual e a continuidade de famílias e dinastias dependerão do homem. Isso contextualiza a intolerância ao homossexualismo que marca o imaginário de muitos povos no mundo e constitui um valor - ou um antivalor, um fantasma onipresente - terrível, ameaçador, de enorme influência e poder em relação à masculinidade. (Zominari, 2003, pp. 35-36)

Compreende-se que essa visão que recrimina a homossexualidade como proteção à vida, à procriação e a continuidade da família, citadas no texto de Zominari (2003), vem das teorias sóciobiológicas e seus determinismos biológicos. Herdeiros de Darwin, tais teóricos pensam que nossos comportamentos são ditados e determinados somente pela evolução e necessidade de adaptação. Para essas teorias, o ato sexual serve apenas à reprodução; não há formas de relacionamento, nem mesmo diferenças afetivas: reproduzir é o principal objetivo e único entre um homem e uma mulher. Por causa da competição, os machos mais fortes e agressivos vencem: "e é essa agressividade masculina hereditária que dá as bases biológicas da dominação do macho sobre a fêmea, da hierarquia e da competitividade entre os homens, e também as bases da guerra" (Badinter, 1993, p. 24).

Goldin (2003) na coluna "Sexo e Amor", da edição n. 121, escreve um texto denominado "Bissexualidade Existe?". Relata que a bissexualidade é uma segunda opção, pois a maioria dos humanos constituem-se monossexual, ou seja, ou se é heterossexual, ou se é homossexual e, ainda, que ser bissexual é privilégio de poucos. Diz: "Ou se trata de um homossexual que, além de sê-lo, possui atração por pessoas do sexo oposto ou então se trata de um heterossexual que eroticamente aceita os representantes do próprio sexo" (Goldin, 2003, p. 38). O autor diz ainda:

A cultura ainda marginaliza a homossexualidade, é provável que a bissexualidade seja um artifício que permite integrar a homossexualidade, já que não aparecia como tendência única do indivíduo. Enquanto a homossexualidade é frequentemente atacada, a bissexualidade é considerada em alguns meios como uma verdadeira proeza. (Goldin, 2003, p. 38)

Na edição n. 122, R. Campos (2003a) em texto intitulado "Afeto é Arma Contra as Drogas", aborda en passant o termo homossexual: ao descrever as novas configurações familiares, indica que a união homossexual é uma delas, sem, no entanto, tecer comentários a respeito. 
No mesmo exemplar, a seção "In-sight" traz um resumo da pesquisa realizada pela Universidade Fernando Pessoa (UFP), com estudantes de alguns cursos, mostrando o preconceito contra homossexuais. Os resultados evidenciam três grupos de estudantes: os não preconceituosos geralmente do curso de psicologia - que explicam a homossexualidade em função de fatores psicossociais; os preconceituosos flagrantes principalmente do curso de engenharia, que entendem a homossexualidade como falha moral ou fraqueza espiritual; e os preconceituosos sutis - predominantemente estudantes de medicina que explicam a homossexualidade de forma biológica (Appolinário, 2003).

No exemplar n. 123, texto intitulado "Sob o Signo do Medo", argumenta que o pânico e as fobias são constantes na clínica e que a forma mais eficaz de tratá-los é a combinação psicoterapia e medicação. Destaca a autora que:

... embora o medo exagerado seja de fato uma angústia brutal, o problema, em termos psiquiátricos, não é dos mais graves. Numa psicoterapia, a primeira tentativa é encontrar sua raiz. São várias as possibilidades: lutos mal elaborados, abandonos infantis, dependência exagerada de alguém de quem se separou, transtornos ligados à sexualidade, dificuldade em lidar com a própria sexualidade ou com a homossexualidade estão entre os principais. Mas o medo é sempre um modo de reagir diante de um conflito. (R. Campos, 2003b, p. 4)

Na edição n. 134, Appolinário (2004), comenta, sem problematização, sobre um ato de protesto e indignação protagonizado por estudantes do curso de Psicologia da Universidade de Murcia (Espanha). Tal ato devia-se, segundo o autor,

da obrigatoriedade de leitura do livro Técnicas de Modificación de Conduta, para cujos autores os problemas de orientação sexual, como a homossexualidade, podem ser tratados com descargas elétricas (70 a 100 volts) ou substâncias químicas causadoras de náuseas [grifos do autor]. (Appolinário, 2004, p. 7)
Vale ressaltar que foi transcrito ipsis literis a fala do autor (Appolinário, 2004), sendo que o mesmo não se referiu ao autor ou autora da obra referenciada. Trata-se de uma informação da seção In-sight, destinada à divulgação de pesquisas e estudos, fatos e novidades.

$\mathrm{Na}$ época, articulava-se, naquele país, uma campanha para banir as obras literárias, consideradas homofóbicas, de todas as instituições de Ensino Superior (Appolinário, 2004).

Por fim, no exemplar n. 126, na seção "Divã", a terapeuta responde a seguinte pergunta da leitora:

Tenho 28 anos e sou homossexual. Gostaria de saber se alguém da minha família também é, mas como sou adotada, não tenho como saber. Meus pais sabem da minha opção e nossa relação é sadia e todos se respeitam. De uns dois anos para cá descobri que meu pai está acessando sites pornográficos gays (só de homens). Guardei aquilo para mim, fiquei muito angustiada, pois não sabia o que fazer. Meus pais são casados há 24 anos, mas ele, toda semana vai a saunas e acessa sites gays masculinos. Nunca conversamos sobre isso, tenho medo de escutar o que ele tem a me dizer. Às vezes, acho que estou sendo preconceituosa. Ele já tem quase 60 anos. $\mathrm{O}$ que faço?

A resposta é a seguinte:

Você não tem de fazer nada, não se meta numa área que não the diz respeito: a intimidade dos seus pais não é assunto seu. Se eles respeitam a sua opção sexual, por que você não respeita a deles? Não se dê o trabalho de procurar raízes genéticas para a homossexualidade, isso não vai fazer a menor diferença na maneira como você conduz sua vida amorosa. Mas parece que você mesma não está confortável com sua opção sexual, com medo de que essa não seja uma escolha saudável ou insegura quanto à sua competência para escolher parcerias dignas, que venham a se aproveitar da situação. Daí essa conversa de ter medo que seu pai pegue alguma doença, ou seja, desrespeitado por algum parceiro. Não precisa se 
preocupar com ele: afinal, ele tem 60 anos e já deve ter aprendido a se cuidar. Não dá mesmo para ter uma conversa verdadeira, se você tem medo de ouvir o que o outro tem a dizer e, além disso, não pode ser sincera (já que descobriu à revelia dele o que ele faz com o computador ou com o tempo livre). (Aratangy, 2003, p. 4)

Apesar de não apresentar uma postura preconceituosa, a autora trata apenas de chamar atenção do/a leitor/a, sem, no entanto, mostrar efetivamente uma posição de acolhida ao problema e, além disso, tratando a homossexualidade como opção e não orientação, como recomenda o Conselho Federal de Psicologia.

O tema homossexualidade pouco está presente nas revistas. Do universo de 25 revistas, 411 matérias foram analisadas. Nas matérias passíveis de entendimento sobre a concepção que organiza o texto, o assunto aparece somente em 8 espaços de 6 exemplares. Nesses raros momentos, o tema homossexualidade se apresenta, ou de forma encoberta por outras vias de acesso, seja como exemplo de outras problemáticas ou respostas de cartas de leitores, ou de forma pouco aprofundado. No restante dos textos, o termo está ausente; tampouco aparecem as expressões decorrentes de sua ampliação, como referenciado no método, razão de não haver comentário sobre os mesmos. É bom que se diga que, do universo analisado, nenhum exemplar da revista traz como matéria de capa o termo homossexualidade ou suas derivações.

Isso parece indicar que, mesmo de forma velada, o preconceito aparece, negando a existência ou camuflando uma forma de problematizar a questão. O não-dito não seria uma forma de preconceito? O não-dito não seria uma forma de estimular o desrespeito à questão da homossexualidade? Para Louro (1997), o não-dito é uma forma de manter a norma; ao se omitir sobre um assunto talvez se pretenda eliminá-lo, ou, pelo menos, pretende-se evitar que os/as 'normais' conheçam e possam desejá-lo. Comenta a autora que, a negação dos/as homossexuais na escola, por exemplo, acaba por confiná-las/os às chacotas e aos desrespeitos, fazendo com que se reco- nheçam como desviantes, detestados ou merecedores de escárnio.

Pode-se ver ainda, que a revista procura, através de especialistas, de diferentes áreas, mas notadamente da Psicologia, agregar um caráter "científico", no sentido de conferir maior credibilidade às matérias. $\mathrm{O}$ discurso veiculado pela revista é vigorosamente psicológico; utiliza teorias psicológicas, autores e termos relativos à psicologia, mesmo quando o emissor não é o especialista da área. Tal discurso teórico afiançado por especialistas, associado ao tipo de linguagem usada, confere um aspecto normativo às matérias. $\mathrm{O}$ texto orienta, aconselha, mostra como devem agir as pessoas.

Por fim, vale salientar que, nos poucos momentos em que aparece alguma problematização quanto à homossexualidade, esta é respaldada pela Psicanálise, mostrando que ainda se vive em um país mergulhado numa "cultura psicanalítica”, como argumenta Figueira (1985, p. 9).

\section{Considerações Finais}

Neste estudo empreendido na revista "Viver Psicologia", em edições editadas no período de 2002 a 2004, pode-se perceber que, das matérias analisadas, diretamente, não se fala sobre o tema da homossexualidade, mesmo que os leitores reivindiquem tal assunto.

Cabe salientar que desde o final da década de 1970, a questão da homossexualidade está em pauta na nossa sociedade: movimentos sociais de defesa à população LGBT são constituídos, ao lado de partidos políticos que se comprometem com a mesma causa, além da posição oficial do CFP no final da década de 1990 e de uma mudança substancial na forma de operar políticas públicas no Brasil. Portanto, o período de publicação analisado coincide com toda essa discussão e mudança de postura. No entanto, a revista não participou das discussões, preferindo adotar uma postura do não-dito.

Tal postura pode ser entendida como preconceito, pois o não-dito é uma forma sutil e discreta, mas quase sempre, eficiente de preservação de tal fenômeno. Torna-se, assim, uma 
forma de manter a norma cultural heterossexista, desenvolvida por uma sociedade machista, cuja homossexualidade é considerada um desvio.

Portanto, a ausência de informação sobre tal assunto só vem reforçar a visão polarizada da nossa sociedade, que construiu uma imagem do homem como hierarquicamente superior à mulher, tornando um campo atravessado por relações de poder, o que se torna extremamente limitante, pois estimula o preconceito, que leva a práticas discriminatórias.

Não se pode esquecer que no caso específico do ideário que norteia a sexualidade, os profissionais das áreas psi ocupam lugar de destaque. As palavras desses profissionais estabelecem o certo e o errado no cotidiano de homens e mulheres, elegendo o adequado desempenho da sexualidade, não a entendendo de forma historicamente construída. Neste sentido, o discurso psicológico e a ausência do discurso psicológico tornam-se elementos importantes na produção da subjetividade.

Desta forma, entende-se que desenvolver discursos e práticas sociais educativas e desvinculados do discurso heterossexista, despreconceituoso e, principalmente, desestigmatizante deve ser o objetivo do discurso psicológico, difundido ou não por meio da mídia, que tem o poder de influir na vida das pessoas, participando do processo de constituição dos sujeitos.

\section{Referências}

Adorno, T. W., \& Horkheimer, M. (1985). Dialética do esclarecimento: Fragmentos filosóficos. Rio de Janeiro, RJ: Zahar.

Appolinário, F. (2003). A força da família [Seção In-sight]. Viver Psicologia, 11(122), 34.

Appolinário, F. (2004). A força dos mitos [Seção In-sight]. Viver Psicologia, 12(134), 7.

Aratangy, L. R. (2003). Relação mãe-bebê [Seção Divã]. Viver Psicologia, 11(126), 4.

Badinter, E. (1993). XY: Sobre a identidade masculina. Rio de Janeiro, RJ: Nova Fronteira.

Bardin, L. (1979). Análise de conteúdo. Lisboa, Portugal: Edições 70.
Berger, P. (1980). Para uma compreensão sociológica da psicanálise. In S. Figueira (Ed.), Psicanálise e ciências sociais (pp. 11-26). Rio de Janeiro, RJ: Francisco Alves.

Buitone, D. H. (1981). Mulher de papel: A representação da mulher na imprensa feminina brasileira. São Paulo, SP: Edições Loyola.

Campos, D. M. S. (1983). Técnicas de modificação de comportamento: Aplicáveis no lar, na escola e na empresa. Petrópolis, RJ: Vozes.

Campos, R. (2003a). Afeto é arma contra as drogas. Viver Psicologia, 11(122), 13-16.

Campos, R. (2003b). Sob o signo do medo. Viver Psicologia, 11(123), 4.

Ceccarelli, P. R. (2008). A invenção da homossexualidade. Bagoas - Estudos Gays: Gênero e Sexualidade, 2(2), 71-93. Recuperado em http:// www.cchla.ufrn.br/bagoas/edic02.html

Conselho Federal de Psicologia. (1999). Resolução CFP $n^{\circ} 001$ de 22 de março de 1999. Normas de atuação para os psicólogos em relação à questão da orientação sexual. Recuperado em http:// site.cfp.org.br/wp-content/uploads/1999/03/ resolucao1999_1.pdf

Conselho Nacional de Justiça. (2013). Resolução $n^{\circ} 175$, de 14 de maio de 2013. Recuperado em http://www.tabelionatolamas.com.br/index. $\mathrm{php} /$ noticias/5-noticias/169-resolucao-no-175-de-14-de-maio-de-2013

Costa, J. F. (1992). A inocência e o vício: Estudos sobre o homoerotismo. Rio de Janeiro, RJ: Relume-Dumará

Figueira, S. A. (1985). Introdução: Psicologismo, psicanálise e ciências sociais na "cultura psicanalítica”. In S. A. Figueira, Cultura da psicanálise (pp. 7-13). São Paulo, SP: Brasiliense.

Foucault, M. (1996). Microfisica do poder. Rio de Janeiro, RJ: Graal.

Freud, S. (1996a). Moral sexual civilizada e doença nervosa moderna (M. A. M. Rego, Trad.). In J. Salomão (Ed.), Edição eletrônica brasileira das obras psicológicas completas de Sigmund Freud [CD-ROM]. Rio de Janeiro, RJ: Imago. (Original publicado em 1908)

Freud, S. (1996b). Três ensaios sobre a teoria da sexualidade: As aberrações sexuais (V. Ribeiro, Trad.). In J. Salomão (Ed.), Edição eletrônica brasileira das obras psicológicas completas de 
Sigmund Freud [CD-ROM]. Rio de Janeiro, RJ: Imago. (Original publicado em 1910a)

Freud, S. (1996c). Leonardo da Vinci e uma lembrança de sua infância (D. Marcondes, Trad.). In J. Salomão (Ed.), Edição eletrônica brasileira das obras psicológicas completas de Sigmund Freud [CD-ROM]. Rio de Janeiro, RJ: Imago. (Original publicado em 1910b)

Freud, S. (1996d). A psicogênese de um caso de homossexualismo numa mulher. In J. Salomão (Ed.), Edição eletrônica brasileira das obras psicológicas completas de Sigmund Freud [CD-ROM]. Rio de Janeiro, RJ: Imago. (Original publicado em 1920)

Goldin, A. (2002). Sofrimento e suas formas de prazer. Viver Psicologia, 10(115), 38.

Goldin, A. (2003). Bissexualidade existe? Viver Psicologia, 11(121), 38.

Guattari, F., \& Rolnik, S. (1986). Micropolitica: Cartografias do desejo. Petrópolis, RJ: Vozes.

Herek, G. M. (2000). Homossexuality. In A. E. Kazdin (Ed.), Encyclopedia of psychology (pp. 149-153). Washington, DC: American Psychological Association.

Jones, E. (1979). Vida e obra de Sigmund Freud. Rio de Janeiro, RJ: Guanabara.

Lacerda, M., Pereira, C., \& Camino, L. (2002). Um estudo sobre as formas de preconceito contra homossexuais na perspectiva das representações sociais. Psicologia: Reflexão e Crítica, 15(1), 165 178. doi:10.1590/S0102-79722002000100018

Le Bon, G. (2001). As opiniões e as crenças. (Reproduzido de Les opinious et le croyances de G. Le Bon, 1911, Paris: Ernest Flammarion). Recuperado em http://www.egov.ufsc.br/portal/sites/ default/files/anexos/24928-24930-1-PB.pdf

Louro, G. L. (1997). Gênero, sexualidade e educação: Uma perspectiva pós-estruturalista. Petrópolis, RJ: Vozes.

Madlener, F., \& Dinis, N. F. (2007). A homossexualidade e a perspectiva foucaultiana. Revista do Departamento de Psicologia-UFF, 19(1), 4960.

Mello, L., Avelar, R. B., \& Maroja, D. (2012). Por onde andam as políticas públicas para a população LGBT no Brasil. Revista Sociedade e Estado, 27(2), 289-312. Recuperado em http:// http:// www.scielo.br/pdf/se/v27n2/a05v27n2
Ministério da Saúde. (2004). Brasil Sem Homofobia: Programa de Combate à Violência e à Discriminação contra GLTB e Promoção da Cidadania Homossexual. Brasília, DF: Autor.

Mott, L. R. B. (2003). Crônicas de um gay assumido. Rio de Janeiro, RJ: Record.

Novelino, A. M. (1989). A cartilha da mãe perfeita: Um discurso normatizador na Psicologia de midia (Dissertação de mestrado, Pontifícia Universidade Católica de São Paulo, SP, Brasil).

Nunan, A. (2003). Homossexualidade: Do preconceito aos padrões de consumo. Rio de Janeiro, RJ: Caravansarai.

Portinari, D. (1989). O discurso da homossexualidade feminina. São Paulo, SP: Brasiliense.

Reis, M. (2003). Superação. Viver Psicologia, 11(120), 4.

Rosenbaum, S. F. R. (1998). Permanência e transformação: A paternidade na revista Pais e Filhos (Dissertação de mestrado, Pontifícia Universidade Católica de São Paulo, SP, Brasil).

Scardua, A., \& Souza, E. A., Filho. (2006). O debate sobre a homossexualidade mediado por representações sociais: Perspectivas homossexuais e heterossexuais. Psicologia: Reflexão e Crítica, 29(3), 482-490. doi:10.1590/S010279722006000300017

Supremo Tribunal Federal. (2011). Supremo reconhece união homoafetiva. Recuperado em http:// www.stf.jus.br/portal/cms/verNoticiaDetalhe. asp?idConteudo $=178931$

Thompson, J. B. (1995). Ideologia e cultura moderna: Teoria social crítica na era dos meios de comunicação de massa. Petrópolis, RJ: Vozes.

Zimerman, D. E. (2004). Manual de técnica psicanalítica: Uma re-visão. Porto Alegre, RS: Artmed.

Zominari, M. de A. (2003). Questão de gênero. Viver Psicologia, 11(121), 34-36. 